\title{
ESPÉCIES ARBÓREAS DA ARBORIZAÇÃO URBANA DO CENTRO DO MUNICÍPIO DE CAMPO GRANDE, MATO GROSSO DO SUL, BRASIL
}

\author{
Lucas Tjhio Cesar Pestana ${ }^{1}$, Flávio Macedo Alves² ${ }^{2}$ Ângela Lúcia Bagnatori Sartori ${ }^{3}$
}

(recebido em 24.09.2010 e aceito para publicação em 15.09.2011)

\section{RESUMO}

As árvores constituem uma parte viva de qualquer cidade, sem as quais o ambiente urbano perderia em agradabilidade, influenciando no clima local, na qualidade do ar e na fauna, principalmente de aves além do fator estético. Este estudo teve por objetivos efetuar o levantamento das espécies arbóreas empregadas no paisagismo urbano do centro do município de Campo Grande, Mato Grosso do Sul, Brasil. Para tanto, foi efetuada a coleta de ramos dos exemplares, que posteriormente foram herborizados e identificados com 0 auxílio de chaves de identificação, literatura pertinente e comparação com material do Herbário CGMS. Foram identificadas 28 famílias, 52 gêneros e 61 espécies, das quais 30 são nativas do Brasil. A família com maior número de espécies foi Leguminosae (11 espécies), seguida de Bignoniaceae (6), Moraceae (5) e Myrtaceae (5), e os gêneros mais representativos foram Ficus (5) e Handroanthus (3). As espécies mais comumente observadas foram Bauhinia variegata L., Caesalpinia peltophoroides Benth., Ficus benjamina L., Inga laurina (Sw.) Willd., Lagerstroemia indica L. e Licania tomentosa (Benth.) Fritsch.

Palavras-chave: Levantamento florístico; Chave de identificação; Espécies nativas.

\footnotetext{
1 Biólogo mestre em Biologia Vegetal pelo Programa de Pós-Graduação em Biologia Vegetal, Universidade Federal de Mato Grosso do Sul, Av. Costa e Silva s/n, 79070-900, Campo Grande, MS, Brasil.

2 Biólogo mestre doutorando em Ciências Biológicas (Botânica) pelo Herbário ESA, Escola Superior de Agricultura "Luiz de Queiroz", Av. Pádua Dias 11, Caixa Postal 09, 13418-900, Piracicaba, SP, Brasil.

3 Bióloga doutora em Biologia Vegetal, docente e pesquisadora dos cursos de graduação de Bacharelado e Licenciatura em Ciências Biológicas e do Programa de Pós-Graduação em Biologia Vegetal, Universidade Federal de Mato Grosso do Sul, Av. Costa e Silva s/n, 79070-900, Campo Grande, MS, Brasil.
} 


\title{
TREE SPECIES USED IN THE URBAN FORESTRY OF THE DOWNTOWN OF CAMPO GRANDE CITY, MATO GROSSO DO SUL, BRAZIL
}

\begin{abstract}
The trees are a living part of any city, and without them the urban environment would lose most of its pleasantness, influencing the local climate, pollution and fauna, besides the aesthetic factor. The aim of this study was to inventory the tree species used in urban landscaping of the downtown of Campo Grande city, Mato Grosso do Sul, Brazil. The methodology included the collection of plant materials that were later herborized and identified through identification keys, pertinent literature and by comparison with the CGMS Herbarium's material. 28 families, 52 genera and 61 species were identified, of which 30 are native to Brazil. The family with the major species number was Leguminosae (11 species), followed by Bignoniaceae (6), Moraceae (5) and Myrtaceae (5), and the most representative genera were Ficus (5) and Handroanthus (3). The most commonly observed species were Bauhinia variegata L., Caesalpinia peltophoroides Benth., Ficus benjamina L., Inga laurina (Sw.) Willd., Lagerstroemia indica L. and Licania tomentosa (Benth.) Fritsch.
\end{abstract}

Keywords: Floristic survey; Identification key; Native species.

\section{INTRODUÇÃO}

As árvores constituem uma parte viva de qualquer cidade, influenciando no clima local e tornando o ambiente mais agradável às pessoas (TAMASHIRO e SARTORI, 1999; SILVA, 2006). Há ainda a possibilidade de a arborização urbana atuar como corredor ecológico, interligando as áreas verdes vegetadas da cidade, como por exemplo, parques, praças e reservas biológicas (RODRIGUES et al., 2002). 
Campo Grande é uma das cidades mais bem arborizadas do Brasil, apresentando um índice de cobertura vegetal de $74 \mathrm{~m}^{2} /$ habitante, enquanto o valor mínimo recomendado pela Sociedade Brasileira de Arborização Urbana (SBAU) é de $15 \mathrm{~m}^{2} /$ habitante (PMCG, 2009).

Apesar de já existirem levantamentos da flora urbana do município de Campo Grande (SEMADUR, 2010a, 2010b; PLANURB, 2009; MEIRA et al., 2001; BORTOLOTTO, 1987; BARROS, 1986), estes estudos tão-somente listaram as espécies das áreas estudadas, sem fornecer meios para sua identificação - e, os dados não foram devidamente divulgados na literatura científica.

Portanto, este projeto teve por objetivos disponibilizar informações sobre a flora urbana de Campo Grande, Mato Grosso do Sul, através do levantamento das espécies arbóreas plantadas no centro de Campo Grande, e fornecer uma chave de identificação taxonômica para as mesmas.

\section{MATERIAL E MÉTODOS}

Este trabalho foi conduzido numa porção do centro do município de Campo Grande, Mato Grosso do Sul, no quadrilátero formado pelas seguintes vias: Av. Fernando Corrêa da Costa, Av. Mato Grosso, Av. Calógeras e R. Padre João Crippa (Figura 1). A área de estudo foi escolhida por apresentar uma riqueza de espécies relativamente alta, por incluir as duas praças centrais do município e várias vias importantes, com maior circulação de pessoas.

Os materiais coletados das plantas, preferencialmente férteis, foram herborizados conforme procedimento convencional (VELOSO, 1992) e identificados com o auxílio de chaves de identificação, literatura pertinente e por comparação com material do Herbário CGMS. O sistema de classificação das Angiospermas usado para este trabalho foi o APG III (2009). Para Leguminosae (ou Fabaceae) são reconhecidas três subfamílias (LEWIS et al., 2005; POLHILL e RAVEN, 1981). O sistema de classificação adotado para Gimnospermas foi o exposto em Souza e Lorenzi (2008). 
Figura 1. Mapas apresentando a área de estudo (destacada em vermelho na imagem de satélite). Escala aproximada (imagem de satélite): 1:500

Figure 1. Maps showing the study site (highlighted in red in the satellite image). Approximate scale (satellite image): 1:500

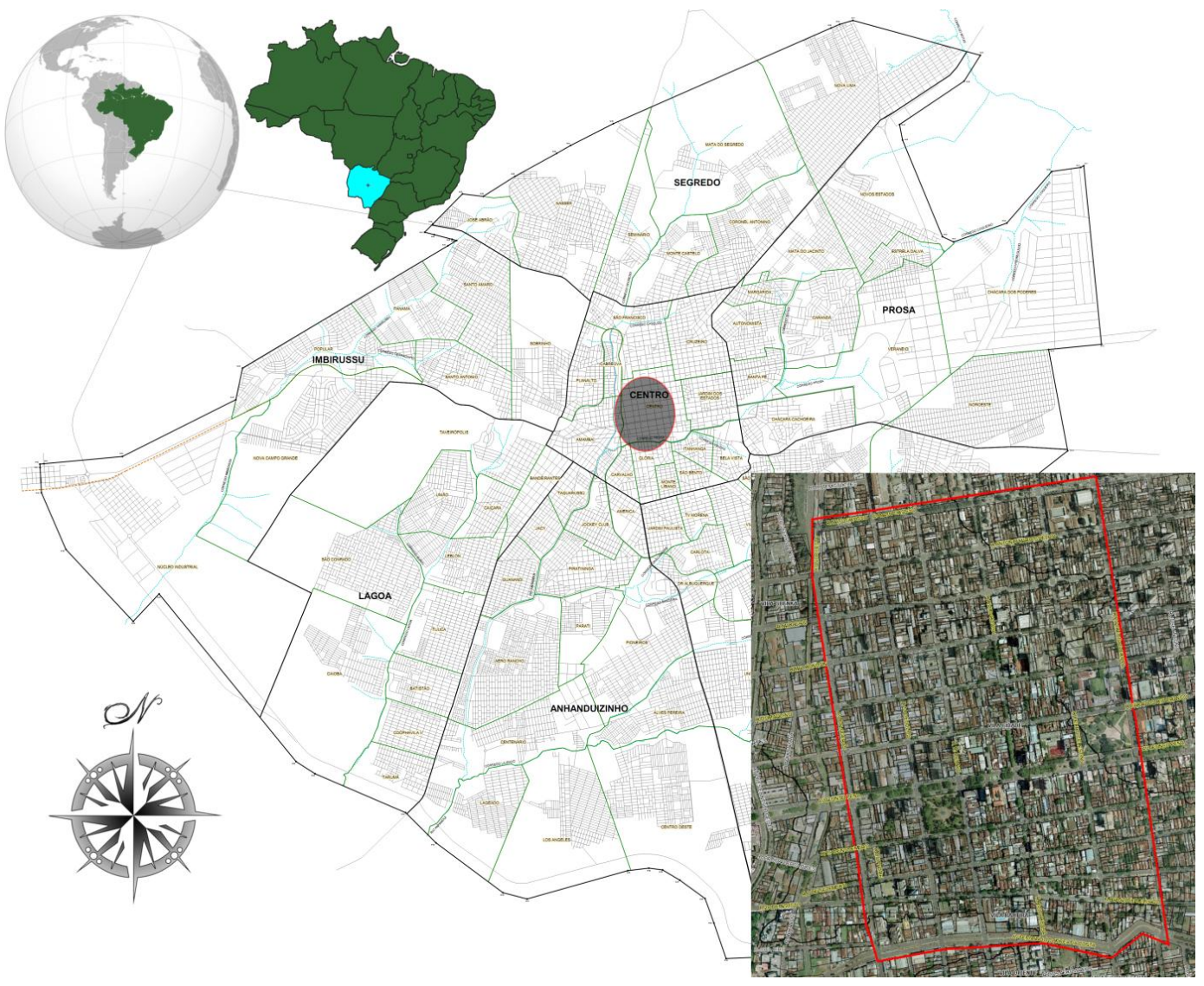

Para identificação e atualização dos táxons de ipês (gêneros Tabebuia e Handroanthus), foram seguidos Grose e Olmstead (2007) e, para as figueiras (Ficus), foi seguido Carauta (1989). Os nomes científicos foram atualizados segundo Tropicos.org (2011) e Forzza et al. (2010).

O cadastramento das espécies foi realizado com o preenchimento de planilha, elaborada com base em Vibrans (2010). A análise morfológica dos materiais foi efetuada in locu e no laboratório de Botânica da Universidade Federal de Mato Grosso do Sul, campus de Campo Grande.

Foram consideradas como árvores as plantas com ramificação próxima do ápice, formando fuste lenhoso (GUEDES-BRUNI et al., 2002). No que tange à morfologia vegetal, foi adotado Gonçalves e Lorenzi (2007). 
Foi construída uma chave de identificação, baseada principalmente em caracteres vegetativos de fácil visualização, sendo o agrupamento das espécies efetuado artificialmente.

As Arecaceae (palmeiras) não foram incluídas na amostra devido à falta de materiais em estágio reprodutivo, o que dificultou ou até mesmo impossibilitou a identificação precisa do material.

\section{RESULTADOS E DISCUSSÃO}

\section{Listagem e avaliação das espécies identificadas}

Foram identificadas 28 famílias, 51 gêneros e 61 espécies (Tabela 1). A família mais representativa foi Leguminosae (11 espécies), seguida de Bignoniaceae (6), Moraceae (5) e Myrtaceae (5). Os gêneros que apresentaram maior número de espécies foram Ficus (5) e Handroanthus (3). As espécies mais comumente encontradas por número de ruas são: Caesalpinia peltophoroides, Pachira aquatica, Lagerstroemia indica, Bauhinia variegata, Ficus microcarpa, Licania tomentosa, Handroanthus impetiginosus, Tibouchina granulosa e Magnolia champaca.

Tabela 1. Listagem das famílias e de espécies arbóreas (exceto Arecaceae) encontradas na arborização urbana de uma região do centro de Campo Grande, Mato Grosso do Sul, Brasil. As espécies nativas do Brasil estão assinaladas com um "ף"

Table 1. Checklist of families and tree species (excuding Arecaceae) found on the urban forestry of an area of Campo Grande's downtown, Mato Grosso do Sul, Brazil. The species native to Brazil are marked with a " $T$ "

\begin{tabular}{cccc}
\hline Família & Nome popular & Nome científico & Localização \\
\hline \multicolumn{2}{c}{ GYMNOSPERMAE } & & 2 \\
\hline Araucariaceae & pinheiro-do-paraná & I Araucaria angustifolia (Bertol.) O. Kuntze & 1 \\
\hline Cupressaceae & $\begin{array}{c}\text { cipreste } \\
\text { mediterrâneo, } \\
\text { cedrinho }\end{array}$ & Cupressus sempervirens L. & 22 \\
\hline Cupressaceae & tuia & Thuja occidentalis L. & 1,9 \\
\hline Cycadaceae & $\begin{array}{c}\text { sagu-das-molucas, } \\
\text { palmeira-sagu, cica } \\
\text { de folhas macias }\end{array}$ & Cycas circinalis L. & 1,22 \\
\hline \multicolumn{2}{c}{ ANGIOSPERMAE } & & $8,7,13,15,19$ \\
\hline Anacardiaceae & manga, mangueira & Mangifera indica L. & Troeira-salsa, \\
\hline Anacardiaceae & \begin{tabular}{c} 
aroeirinha, bálsamo, \\
\hline
\end{tabular}
\end{tabular}




\begin{tabular}{|c|c|c|c|}
\hline & falso-chorão & & \\
\hline Anacardiaceae & $\begin{array}{c}\text { pitombeira, } \\
\text { cajazeiro, cajá-mirim }\end{array}$ & I Spondias mombin L. & 2 \\
\hline Annonaceae & fruta-do-conde, ata & Annona sp. & 12 \\
\hline Apocynaceae & espirradeira & Nerium oleander $\mathrm{L}$. & 13,18 \\
\hline Apocynaceae & $\begin{array}{l}\text { jasmim-manga, } \\
\text { árvore-pagode }\end{array}$ & I Plumeria acutifolia Poir. & 2,21 \\
\hline Apocynaceae & chapéu-de-napoleão & II Thevetia peruviana (Pers.) K. Schum. & 6 \\
\hline Asparagaceae & iuca, iuca-elefante & Yucca elephantipes Regel ex Trel. & 1,2 \\
\hline Bignoniaceae & $\begin{array}{l}\text { espatódia, flor- } \\
\text { d'água, tulipeira, } \\
\text { árvore-da-bisnaga }\end{array}$ & Spathodea campanulata P. Beauv. & $2,3,4,21$ \\
\hline Bignoniaceae & $\begin{array}{l}\text { ipê-amarelo, ipê- } \\
\text { tabaco }\end{array}$ & $\begin{array}{l}\text { I Handroanthus chrysotrichus (Mart. ex DC.) } \\
\text { Mattos }\end{array}$ & 2 \\
\hline Bignoniaceae & $\begin{array}{l}\text { ipê-roxo-sete-folhas, } \\
\text { pau-d'arco-roxo }\end{array}$ & II Handroanthus heptaphyllus (Vell.) Mattos & 3 \\
\hline Bignoniaceae & ipê-roxo & $\begin{array}{l}\text { I Handroanthus impetiginosus (Mart. ex DC.) } \\
\text { Mattos }\end{array}$ & $1,2,3,6,12,21,13,17$ \\
\hline Bignoniaceae & $\begin{array}{l}\text { ipê-branco, pau-de- } \\
\text { cerrado, pau-d'arco }\end{array}$ & I Tabebuia roseo-alba (Ridl.) Sandwith & 2 \\
\hline Bignoniaceae & $\begin{array}{l}\text { ipê-mirim, ipê-de- } \\
\text { jardim }\end{array}$ & Tecoma stans (L.) Juss. ex Kunth & 1,3 \\
\hline Chrysobalanaceae & oiti & I Licania tomentosa (Benth.) Fritsch. & $\begin{array}{c}1,3,6,8,9,12,13,15 \\
20,21,22,23\end{array}$ \\
\hline Combretaceae & $\begin{array}{c}\text { sete-copas, chapéu- } \\
\text { de-sol }\end{array}$ & Terminalia catappa L. & $4,12,21$ \\
\hline Euphorbiaceae & sangra-d'água & I Croton urucurana Baill. & 2 \\
\hline Lecythidaceae & jequitibá & I Cariniana estrellensis (Raddi) Kuntze & 1 \\
\hline $\begin{array}{l}\text { Leguminosae } \\
\text { (Caesalpinioideae) }\end{array}$ & $\begin{array}{l}\text { pata-de-vaca, unha- } \\
\text { de-vaca, árvore-de- } \\
\text { são-tomás }\end{array}$ & Bauhinia variegata $\mathrm{L}$. & $\begin{array}{l}1,3,4,6,7,8,12,14 \\
15,17,18,20,21,22\end{array}$ \\
\hline $\begin{array}{c}\text { Leguminosae } \\
\text { (Caesalpinioideae) }\end{array}$ & pau-brasil & I Caesalpinia echinata Lam. & 1 \\
\hline $\begin{array}{c}\text { Leguminosae } \\
\text { (Caesalpinioideae) }\end{array}$ & sibipiruna & I Caesalpinia peltophoroides Benth. & $\begin{array}{l}2,3,4,6,7,8,10,11 \\
12,13,14,15,16,18 \\
19,20,21,22,23,24 \\
\end{array}$ \\
\hline $\begin{array}{c}\text { Leguminosae } \\
\text { (Caesalpinioideae) }\end{array}$ & flamboyant & Delonix regia (Bojer ex Hook.) Raf. & $2,6,17,22$ \\
\hline $\begin{array}{l}\text { Leguminosae } \\
\text { (Caesalpinioideae) }\end{array}$ & $\begin{array}{c}\text { cássia-amarela, } \\
\text { canafístula-de- } \\
\text { besouro }\end{array}$ & Senna spectabilis (DC.) H.S. Irwin \& Barneby & 2 \\
\hline $\begin{array}{l}\text { Leguminosae } \\
\text { (Mimosoideae) }\end{array}$ & $\begin{array}{l}\text { timbaúva, tamboril, } \\
\text { orelha-de-negro }\end{array}$ & $\begin{array}{l}\text { I Enterolobium contortisiliquum (Vell.) } \\
\text { Morong. }\end{array}$ & 2 \\
\hline $\begin{array}{l}\text { Leguminosae } \\
\text { (Mimosoideae) }\end{array}$ & $\begin{array}{l}\text { ingá-branco, ingá- } \\
\text { mirim, ingaí }\end{array}$ & I Inga laurina (Sw.) Willd. & $1,2,3,12$ \\
\hline $\begin{array}{l}\text { Leguminosae } \\
\text { (Mimosoideae) }\end{array}$ & leucena & Leucaena leucocephala (Lam.) de Wit. & $3,9,11$ \\
\hline $\begin{array}{l}\text { Leguminosae } \\
\text { (Papilinoideae) }\end{array}$ & $\begin{array}{c}\text { sombreiro, } \\
\text { palheteira, sombra- } \\
\text { de-vaca, cássia-roxa }\end{array}$ & I Clitoria fairchildiana Howard & $2,13,15,22$ \\
\hline $\begin{array}{l}\text { Leguminosae } \\
\text { (Papilinoideae) }\end{array}$ & $\begin{array}{l}\text { mulungu (não } \\
\text { identificado) }\end{array}$ & Erythrina sp. & 1 \\
\hline $\begin{array}{l}\text { Leguminosae } \\
\text { (Papilinoideae) }\end{array}$ & tipa, tipuana & Tipuana tipu (Benth.) Kuntze & 1 \\
\hline Lythraceae & $\begin{array}{l}\text { resedá, extremosa, } \\
\text { escumilho }\end{array}$ & Lagerstroemia indica L. & $\begin{array}{c}3,4,6,7,8,9,10,12 \\
14,15,16,18,19,20 \\
21,22,23 \\
\end{array}$ \\
\hline Magnoliaceae & magnólia-amarela & Magnolia champaca L. & $2,6,7,10,14,15$ \\
\hline Magnoliaceae & magnólia-branca & Magnolia grandiflora L. & 1 \\
\hline Malpighiaceae & $\begin{array}{l}\text { acerola, cerejeira- } \\
\text { das-antilhas }\end{array}$ & Malpighia glabra L. & 21 \\
\hline Malvaceae & hibisco, papoula, & Hibiscus rosa-sinensis L. & $7,8,15,20,21$ \\
\hline
\end{tabular}




\begin{tabular}{|c|c|c|c|}
\hline & mimo-de-vênus & & \\
\hline Malvaceae & $\begin{array}{l}\text { chico-magro, pau- } \\
\text { de-mutamba }\end{array}$ & I Guazuma ulmifolia Lam. & 1 \\
\hline Malvaceae & $\begin{array}{l}\text { paineira-rosa, } \\
\text { cimeira }\end{array}$ & I Ceiba speciosa (A. St.-Hil.) Ravenna & $1,2,14$ \\
\hline Malvaceae & $\begin{array}{l}\text { monguba, cacau- } \\
\text { selvagem }\end{array}$ & Pachira aquatica Aubl. & $\begin{array}{c}1,2,3,6,7,8,10,11 \\
12,14,15,18,19,21 \\
22,23,24\end{array}$ \\
\hline Melastomataceae & $\begin{array}{l}\text { orelha-de-onça, } \\
\text { quaresmeira-anã }\end{array}$ & I Tibouchina grandifolia Cogn. & 1 \\
\hline Melastomataceae & quaresmeira-roxa & I Tibouchina granulosa (Desr.) Cogn. & $2,7,12,17,19,21,22$ \\
\hline Meliaceae & $\begin{array}{c}\text { canjerana, } \\
\text { carrapeta, açafroa, } \\
\text { cedrorana, taúva }\end{array}$ & I Guarea guidonia (L.) Sleumer & 1 \\
\hline Moraceae & figueira-de-jardim & Ficus auriculata Lour. & 1,2 \\
\hline Moraceae & ficus, figueira & Ficus benjamina L. & 3 \\
\hline Moraceae & $\begin{array}{l}\text { falsa-seringueira, } \\
\text { ficus italiano }\end{array}$ & Ficus elastica Roxb. ex Hornem. & 2 \\
\hline Moraceae & laurel-da-índia & Ficus microcarpa L. f. & $\begin{array}{c}2,5,6,7,8,9,12,16 \\
19,21,22,23\end{array}$ \\
\hline Moraceae & $\begin{array}{l}\text { figueira (não } \\
\text { identificada) }\end{array}$ & Ficus sp. & 3 \\
\hline Myrtaceae & escova-de-garrafa & Callistemon citrinus (Curtis) Skeels & $6,21,22$ \\
\hline Myrtaceae & pitangueira & I Eugenia uniflora L. & 1 \\
\hline Myrtaceae & eugênia & II Eugenia sprengelli DC. & 18 \\
\hline Myrtaceae & goiabeira & II Psidium guajava L. & $2,6,22$ \\
\hline Myrtaceae & jamelão, jambolão & Syzygium cumini (L.) Skeels. & 2,6 \\
\hline Nyctaginaceae & $\begin{array}{l}\text { primavera, } \\
\text { bouganville }\end{array}$ & I Bougainvillea glabra Choisy & 2 \\
\hline Oleaceae & ligustro, alfeneiro & Ligustrum lucidum W.T. Aiton & $3,6,11,12,18$ \\
\hline Polygonaceae & $\begin{array}{l}\text { pau-formiga, pau- } \\
\text { de-formiga }\end{array}$ & I Triplaris americana L. & 12,22 \\
\hline Rubiaceae & $\begin{array}{l}\text { pau-de-mulato, pau- } \\
\text { mulato-da-várzea }\end{array}$ & I Calycophyllum multiflorum Griseb. & 1,2 \\
\hline Rutaceae & limoeiro, limão-rosa & Citrus $\times$ limon (L.) Osbeck & $4,7,19$ \\
\hline Rutaceae & murta-de-cheiro & Murraya paniculata (L.) Jack & $4,7,19$ \\
\hline Sapotaceae & $\begin{array}{c}\text { pimenteira-de- } \\
\text { arancuã, leiteirinho, } \\
\text { uvinha }\end{array}$ & $\begin{array}{l}\text { I Chrysophyllum marginatum (Hook. \& Arn.) } \\
\text { Radlk. }\end{array}$ & 1 \\
\hline Urticaceae & embaúba, embaúva & I Cecropia pachystachya Trécul & 1,3 \\
\hline
\end{tabular}

\section{LEGENDA REFERENTE À LOCALIZAÇÃO / LABELS CONCERNING LOCATION:}

1 = Praça Ary Coelho; 2 = Pça. da República ("Praça do Rádio Clube"); 3 = Avenida Afonso

Pena; 4 = Av. Calógeras; $5=$ Av. Fernando Corrêa da Costa; $6=$ Av. Mato Grosso; $7=$ Rua 7 de Setembro; 8 = R. 13 de Maio; 9 = R. 14 de Julho; 10 = R. 15 de Novembro; 11 = R. 26 de Agosto; 12 = R. Antônio Maria Coelho; 13 = R. Barão de Melgaço; $14=$ R. Barão do Rio Branco; $15=$ R. Dom Aquino; $16=\mathrm{R}$. Imigrantes; $17=\mathrm{R}$. Íria Loureiro Viana; $18=\mathrm{R}$. Joaquim Murtinho; 19 = R. Marechal Cândido Mariano Rondon; $20=$ R. Maracaju; $21=R$. Padre João Crippa; 22 = R. Pedro Celestino; 23 = R. Rui Barbosa; $24=$ Travessa Lydia Baís (R. do Padre). 
Espécies como Bauhinia variegata, Caesalpinia peltophoroides, Eugenia uniflora, Ficus elastica (Figura 2), Licania tomentosa, Magnolia champaca, Mangifera indica, Nerium oleander, Plumeria acutifolia e Terminalia catappa são muito comuns na arborização urbana brasileira (BACKES e IRGANG, 2002; ENERSUL, 2005; MACHADO et al., 1992; PRANCE, 1975; TAMASHIRO e SARTORI, 1999). Porém, outras espécies como Calycophyllum multiflorum, Cariniana estrellensis, Cecropia pachystachya, Guarea guidonia, Inga laurina, Syzygium cumini e Thevetia peruviana, são de uso incomum.

Figura 2. Ficus elastica (falsa-seringueira), na Praça da República ("Praça do Rádio Clube”) Figure 2. Ficus elastica (Indian rubber tree), in Praça da República ("Praça do Rádio Clube")

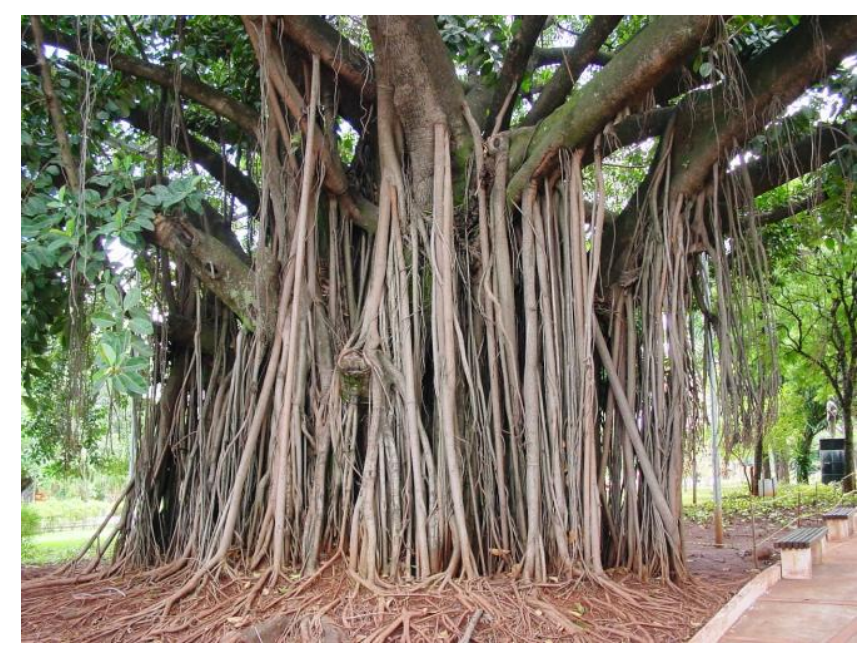

Foto de A.J. Lopes

Das espécies coletadas, 30 são nativas do Brasil (marcadas com um "ণ" na Tabela 1) (SEMADUR, 2010b; ENERSUL, 2005), totalizando quase metade (49\%) do total de espécies amostradas. Destas, são nativas do Pantanal segundo Pott e Pott (1994) as espécies Calycophyllum multiflorum, Cecropia pachystachya, Guarea guidonia, Guazuma ulmifolia, Handroanthus heptaphyllus, Handroanthus impetiginosus (Figura 2), Thevetia peruviana e Triplaris americana, perfazendo aproximadamente 13\% do total de espécies amostradas. Cariniana estrellensis, que ocorre na floresta pluvial e em matas de galeria do Brasil Central, e Guazuma ulmifolia, que ocorre em quase todo o Brasil em floresta estacional (ALMEIDA et al., 1998), somam $3 \%$ do total amostrado. O número significativo de espécies nativas detectadas na arborização urbana de Campo Grande pode ser explicado pela iniciativa da Prefeitura de incentivar plantio de espécies nativas (OLIVEIRA, 2010). 
Figura 3. Handroanthus heptaphyllus (ipê-roxo, à esquerda), na Praça da República ("Praça do Rádio Clube"), e Handroanthus impetiginosus (pau-d'arco-roxo, à direita), na Avenida Afonso Pena.

Figure 3. Handroanthus heptaphyllus (tajy, left), in Praça da República ("Praça do Rádio Clube"), and Handroanthus impetiginosus (pink trumpet tree, right), in Avenida Afonso Pena.

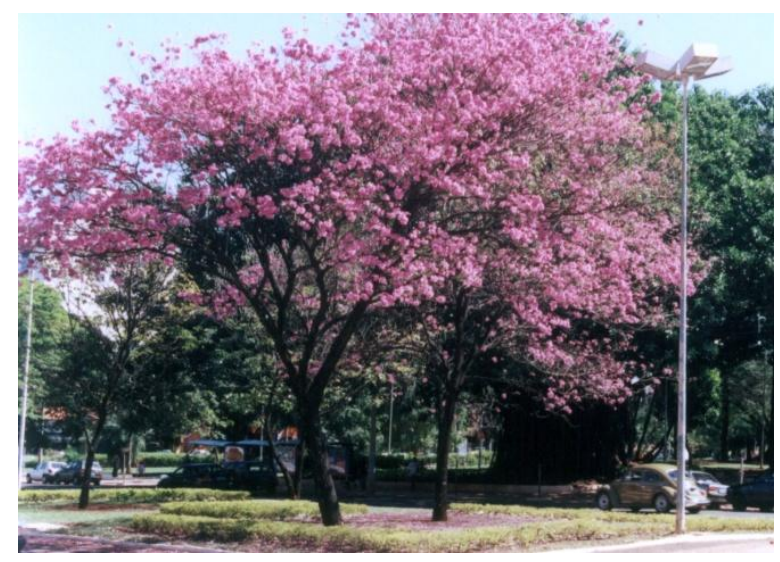

Foto de Jefferson França

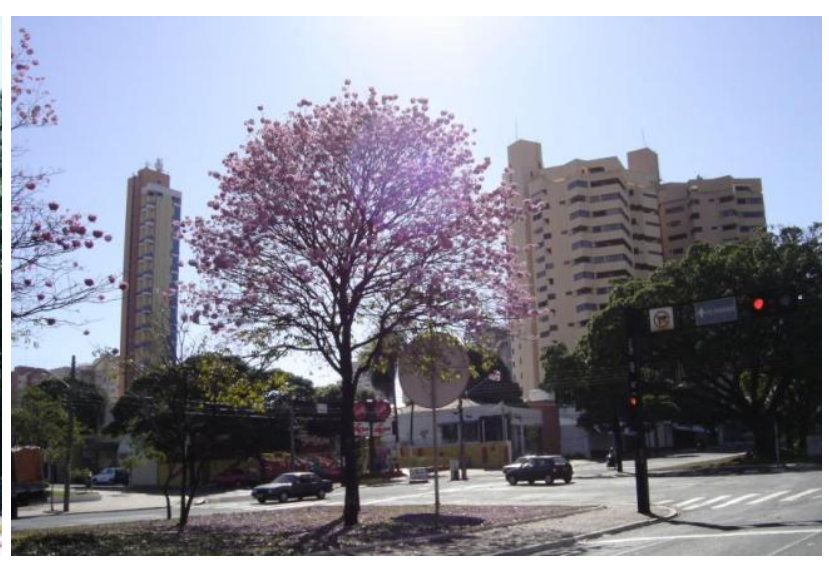

Foto de Corumbaiano87

A exemplo de outras espécies, a presença um único espécime (PLANURB, 2009; SEMADUR, 2010b) de Cecropia pachystachya (embaúba) na arborização urbana de Campo Grande - especificamente, na Praça Ary Coelho (Figura 3) - possivelmente se dá em função do seu hábito invasor. Segundo Lorenzi (2008), a espécie é pioneira, característica de áreas abertas e ocorre em quase todo o Brasil; Pott e Pott (1994) comentam brevemente um possível uso ornamental para Cecropia pachystachya, mas, em contrapartida, citam que os ramos da mesma são ocos, colonizados por formigas do gênero Azteca, sendo muito comum a mirmecofilia. Considerando esses aspectos, pode-se supor que o indivíduo encontrado não tenha sido plantado intencionalmente, mas simplesmente tenha se dispersado naturalmente até seu lugar atual. 
Figura 4. Cecropia pachystachya (embaúba) na Praça Ary Coelho.

Figure 4. Cecropia pachystachya (ambay) in Praça Ary Coelho.

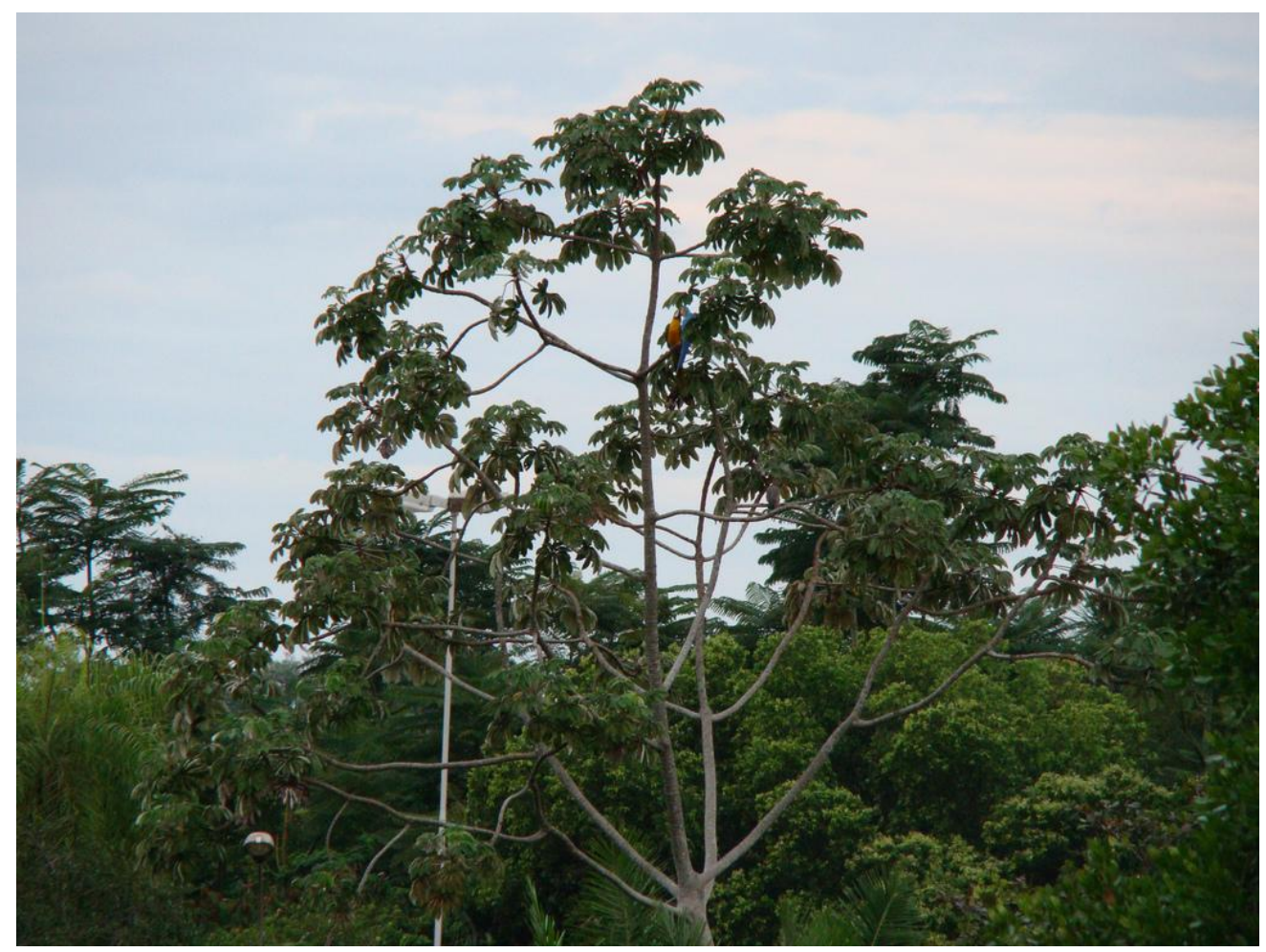

Foto de Daniel Gonçalves

Nas duas praças amostradas, República e Ary Coelho (Figura 4), foram encontradas, respectivamente, 26 e 24 espécies.

Figura 5. Praça da República ("Praça do Rádio Clube”) (à esquerda) e Praça Ary Coelho (à direita).

Figure 5. Praça da República ("Praça do Rádio Clube") (left) and Praça Ary Coelho (right).

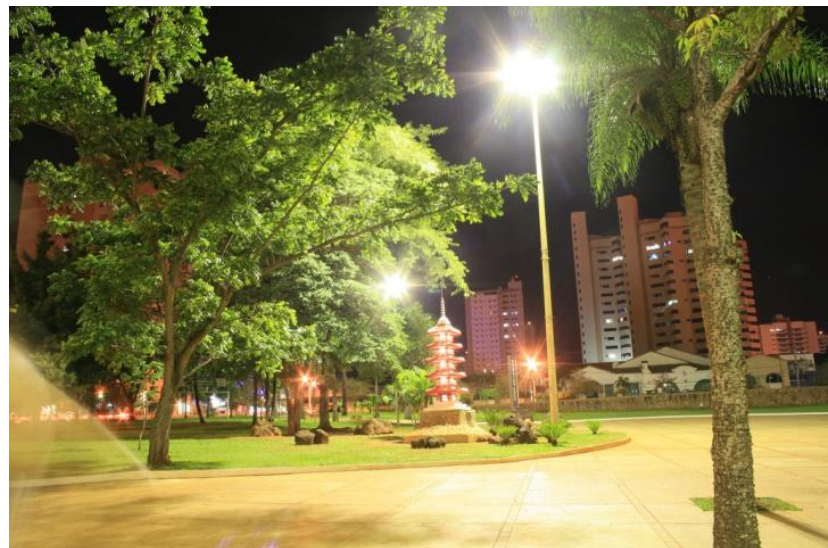

Foto de João Marques

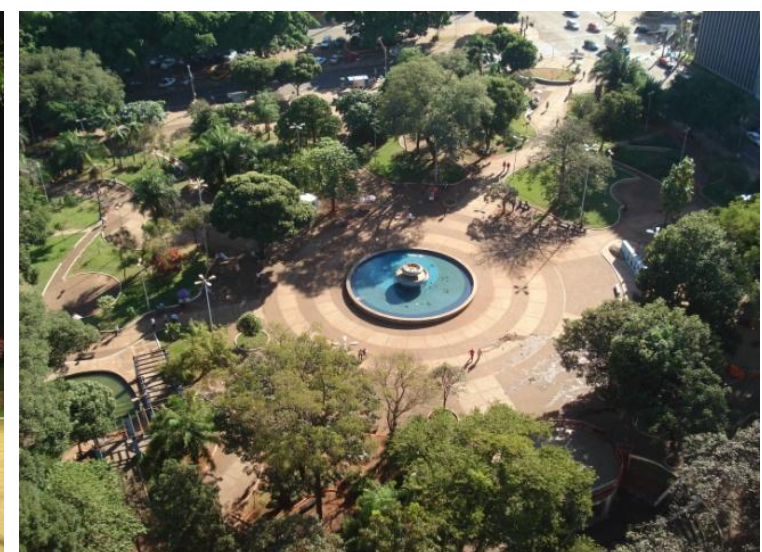

Foto de Luiz Fernando de Britto Moreira da Costa

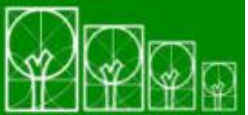

$\mathbf{S} \cdot \mathbf{B} \cdot \mathbf{A} \cdot \mathbf{U}$ Soc. Bras. de Arborização Urbana 
Neste trabalho, foram registrados muitos indivíduos de Caesalpinia peltophoroides (sibipirunas) (Figura 5), presentes em $83 \%$ do total das vias amostradas. De acordo com informações fornecidas pela prefeitura, os indivíduos desta espécie perfazem mais de $25 \%$ das 36 mil árvores existentes na região central do município de Campo Grande (SEMADUR, 2010b.)

Figure 6. Caesalpinia peltophoroides (sibipiruna) na Rua Padre João Crippa

Figure 6. Caesalpinia peltophoroides (false brazilwood) at Rua Padre João Crippa

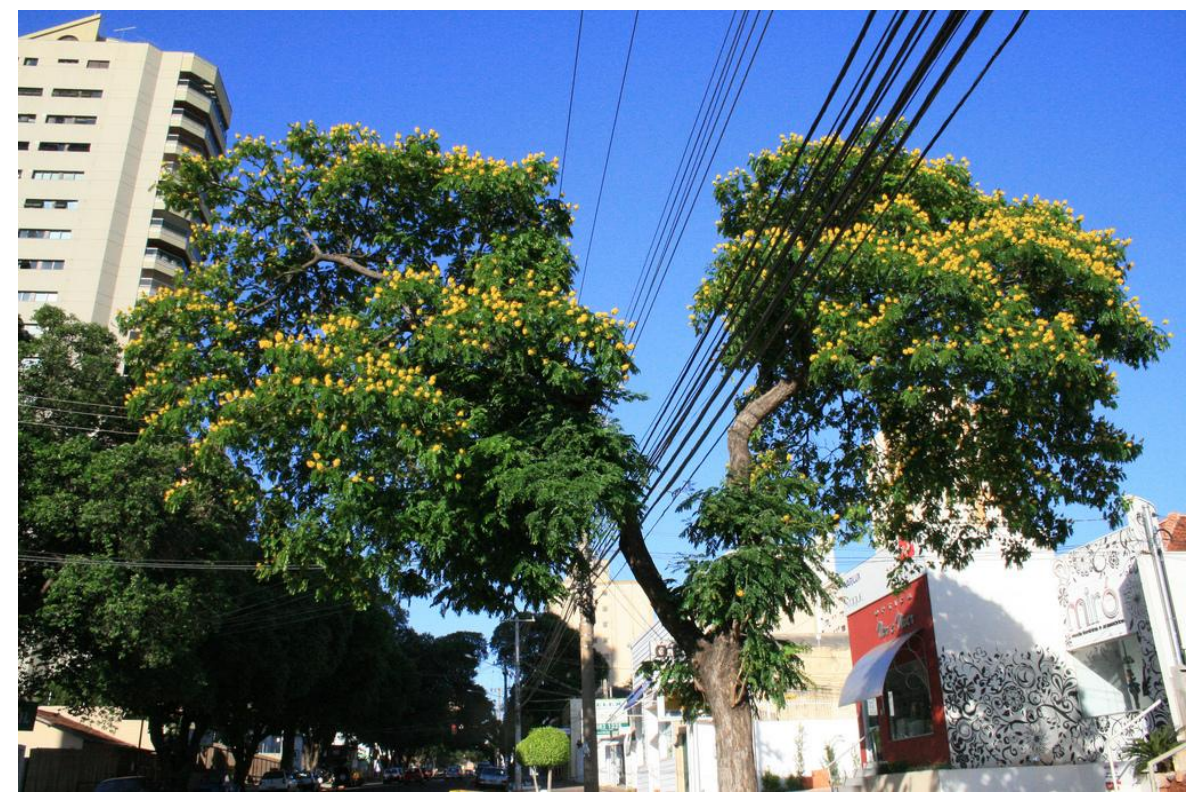

Foto de João Marques

\section{Chave de identificação para as espécies amostradas}

\section{Instruções de uso:}

Uma chave de identificação é uma ferramenta desenvolvida para se identificar organismos. Os passos da chave são compostos por pares de alternativas mutuamente excludentes. Para facilitar o uso desta chave, após os termos técnicos são fornecidas entre colchetes [] expressões mais acessíveis. Para utilizá-la, verifique se o material avaliado condiz com a característica descrita em cada passo. 
Exemplo 1: Com um ramo de pata-de-vaca (Bauhinia variegata), o leitor percorrerá a chave do seguinte modo: Passo 1. (folhas compostas) $\rightarrow$ Passo 2. (folhas bifolioladas) $\rightarrow$ Passo 3. (folha com dois folíolos) $\rightarrow$ Bauhinia variegata.

Caso o material analisado não se adeque ao descrito na primeira alternativa (digamos, 2.), deve-se localizar a segunda (2') e prosseguir a partir deste ponto.

Exemplo 2: Com um ramo de pau-brasil (Caesalpinia echinata), o leitor percorrerá a chave do seguinte modo: Passo 1. (folhas compostas) $\rightarrow$ Passo 2' (folhas pinadas ou bipinadas) $\rightarrow$ Passo 11' (folhas bipinadas) $\rightarrow$ Passo 21. (foliólulos alternos e ramos com acúleos) $\rightarrow$ Caesalpinia echinata.

É recomendável o uso de um glossário ou dicionário ilustrado (GONÇALVES e LORENZI, 2007) para os que não têm familiaridade com a terminologia botânica.

Para auxiliar no reconhecimento apenas das famílias botânicas, podem ser utilizadas outras chaves de identificação (AGAREZ et al., 1994) mais abrangentes ou guias ilustrados (SOUZA e LORENZI, 2008). Para verificar gêneros e espécies, são particularmente úteis o site Tropicos.org (2011) e o dicionário de bolso de Mabberley (2008).

1. - Folhas compostas [divididas parcial ou totalmente em folhinhas]

2. - Folhas bifolioladas [com duas folhinhas], trifolioladas [com três folhinhas] ou palmadas [na forma da palma de uma mão]

3. - Folhas bifolioladas [divididas em duas folhinhas] Bauhinia variegata

3' - Folhas com três a sete folíolos[folhinhas]

4. - Folíolos deltóides [triangulares] com ápice retuso [com reentrância] Erythrina sp.

4' - Folíolos com outras características

5. - Folha com três folíolos, nunca palmadas Clitoria fairchildiana

$5^{\prime}$ - Folha com quatro a sete folíolos, sempre palmada

6.- Folíolos velutinos [pêlos macios] em ambas as faces Tabebuia chrysotricha

6' - Folíolos glabros, se velutinos, somente na face inferior

7. - Ápice foliolar obtuso [ângulo maior que $90^{\circ}$ ] Pachira aquatica

$7^{\prime}$ - Ápice foliolar acuminado [terminando numa pequena ponta]

8. - Folhas dispostas espiraladamente nos ramos Ceiba speciosa

8 ' - Folhas opostas cruzadas [pares de folhas saindo de pontos opostos do ramo]

9. - Margem dos folíolos totalmente serreada [em forma de serra]; base de pelo menos um dos folíolos assimétrica; folhinhas geralmente ovais Handroanthus heptaphyllus 9' - Margem dos folíolos inteira [lisa] ou parcialmente serreada; base de todos dos folíolos cuneada [ângulo de $45^{\circ}$ ] ou arredondada; folhinhas geralmente elípticas [em forma de boca] 
10. - Pecíolos, peciólulos [hastes das folhinhas] e folíolos velutinos na face inferior

Tabebuia roseo-alba

10' - Pecíolos, peciólulos [hastes das folhinhas] e folíolos glabros [sem pêlos] na face inferior Handroanthus impetiginosus

2 ' - Folhas pinadas [forma de pina (lembrando penas de ave), subdivididas em folhinhas apenas uma vez] ou bipinadas [subdivididas em pinas duas vezes]

11. - Folhas pinadas [lembrando penas de ave, subdivididas em folhinhas apenas uma vez] 12. - Planta com crescimento monopodial [com todos os ramos saindo do ápice do tronco] Cycas circinalis 12 - Planta com crescimento simpodial [com ramos saindo em mais de um ponto no tronco]

13. - Folhas paripinadas [terminando em um par de folhinhas na ponta]

14. - Folíolos [folhinhas] com margem levemente serreada [em forma de serra] .... Schinus molle

14' - Folíolos com margem inteira [lisa]

15. - Raque alada [haste central da folha com expansões laterais]; folhas com até sete folíolos Inga laurina

$15^{\prime}$ - Raque não alada; folhas com mais de sete folíolos

16. - Folíolos de $2-4 \mathrm{~cm}$ de comprimento, de base assimétrica e nervuras secundárias evidentes na face inferior Senna spectabilis 16' - Folíolos de 5,5-11 cm de comprimento, de base atenuada [a lâmina vai se afinando em direção à haste] e nervuras secundárias não evidentes na face inferior Guarea guidonia

$13^{\prime}$ - Folhas imparipinadas [terminando em uma folhinha na ponta] 17. - Lenticelas [pequenas fendas ou buracos] evidentes no caule

Spathodea campanulata

$17^{\prime}$ - Lenticelas não evidentes no caule

18. - Presença de glândulas aromáticas [pontos translúcidos, visíveis contra a luz] na lâmina do folíolo Murraya paniculata

18' - Ausência de glândulas aromáticas no folíolo

19. - Folíolos assimétricos, ápice acuminado [terminando numa pequena ponta] ... Spondias mombin

19' - Folíolos simétricos, ápice retuso ou agudo

20. - Folíolos de margem lisa e ápice retuso [com reentrância] Tipuana tipu $20^{\prime}$ - Folíolos de margem denteada e ápice agudo [ângulo menor que $90^{\circ}$ ]

Tecoma stans

$11^{\prime}$ - Folhas bipinadas [subdivididas em pinas duas vezes] 
21. - Foliólulos [folhinhas menores] dispostos alternadamente; ramos providos de acúleos ["espinhos" que se destacam facilmente] Caesalpinia echinata 21 ' - Foliólulos [folhinhas menores] opostos; ramos desprovidos de acúleos 22. - Copa da árvore em forma de domo achatado, raízes tabulares [em forma de tábuas] geralmente presentes Delonix regia $22^{\prime}$ - Árvores sem os caracteres acima

23. - Raque foliar [haste central da folha] sem nectários extra-florais; ápice dos foliólulos [folhinhas] desprovido de apículo ou múcron [pontinha]

Caesalpinia peltophoroides

23' - Raque foliar com nectários extra-florais; ápice dos foliólulos provido de apículo ou múcron

24. - Nectários extra-florais presentes em todos os pares de pinas, inclusive nas raques secundárias

Enterolobium contortisiliquum 24' - Nectários extra-florais presentes somente no primeiro e no último par de pinas [agrupamentos de folhinhas menores], ausentes nas raques secundárias [hastes centrais que sustentam as folhinhas menores] Leucaena leucocephala 1 ' - Folhas simples [indivisas]

25. - Folhas imbricadas [sobrepostas]

26. - Árvore geralmente de até $15 \mathrm{~m}$ de altura; ausência de glândula resinosa nas folhas; folhas com cerca de $3 \mathrm{~cm}$ de comprimento Thuja occidentalis 26' - Árvore de 20-30 m de altura; presença de glândula resinosa nas folhas; folhas com até $20 \mathrm{~cm}$ de comprimento Cupressus sempervirens

$25^{\prime}$ - Folhas não imbricadas

27. - Lâmina foliar profundamente recortada Cecropia pachystachya 27 ' Lâmina foliar inteira

28. - Folhas verticiladas [mais de uma folha inserida no mesmo nó] Nerium oleander

28 ' - Folhas dispostas alternadamente ou opostas ao longo do ramo 29. - Folhas alternas

30. - Folhas alternas dísticas [no mesmo lado do ramo] 31. - Margem foliar inteira Annona sp. 31' - Margem foliar serrilhada Guazuma ulmifolia 30 ' - Folhas alternas espiraladas 32. - Planta provida de ócrea [bainha que reveste o ramo no ponto de inserção das folhas] Triplaris americana 32' - Planta desprovida de ócrea 33. - Arquitetura da copa semelhante a um candelabro; inexistência de flores e frutos (Gimnosperma) Araucaria angustifolia 
33' - Arquitetura da copa não semelhante a um candelabro; produção de flores e frutos (Angiosperma)

34. - Folhas aromáticas, odor de terebentina [cheiro de manga]

Mangifera indica

34' - Folhas não aromáticas

35. - Folhas sésseis [sem haste], congestas [densamente agrupadas] no ápice dos ramos Yucca elephantipes

$35^{\prime}$ - Folhas pecioladas [com haste], laxas [espaçadas] ao longo dos ramos

36. - Plantas latescentes [produzem látex]

37. - Folhas com cerca de $20 \mathrm{~cm}$ de largura Ficus auriculata

$37^{\prime}$ - Folhas com até $10 \mathrm{~cm}$ de largura

38. - Pecíolo [haste] de comprimento igual ou maior que $5 \mathrm{~cm}$; presença de nectários extra-florais na base da folha; folhas obovais

Croton urucurana 38' - Pecíolo de comprimento menor que $5 \mathrm{~cm}$; ausência de nectários extraflorais; folhas de não obovais

39. - Pecíolo com cerca de $5 \mathrm{~mm}$ de comprimento; ápice foliar obtuso ou apiculado Thevetia peruviana 39' - Pecíolo com mais de $5 \mathrm{~mm}$ de comprimento; ápice foliar acuminado, obtuso ou agudo, raro apiculado

40. - Folha discolor [margem e lâmina de cores diferentes]; ápice foliar obtuso, raro agudo Ficus microcarpa 40' - Folha concolor [margem e lâmina da mesma cor]; ápice acuminado; raro com apículo

41. - Base foliar arredondada a cordada [em forma de coração] Ficus sp. 41' - Base foliar atenuada [a lâmina vai se afinando em direção à haste] 42. - Ausência de estípulas ["escamas"] protegendo as gemas no ápice dos ramos; nervuras secundárias fortemente discolores em relação à lâmina foliar Plumeria acutifolia 42 - Presença de estípulas protegendo as gemas no ápice dos ramos; nervuras secundárias concolores em relação ao limbo foliar

43. - Folhas cartáceas [textura semelhante à da cartolina] com até $7 \mathrm{~cm}$ de comprimento Ficus benjamina $43^{\prime}$ - Folhas coriáceas [textura semelhante à do couro] com mais de $10 \mathrm{~cm}$ de comprimento Ficus elastica

36' - Plantas não latescentes [não produzem látex]

44. - Folhas brilhantes na face superior, velutinas na face inferior

Magnolia grandiflora 
44' - Maioria das espécies com folhas opacas [sem brilho] na face superior, glabras [sem pêlos] na face inferior

45. - Presença de lenticelas [pequenas fendas ou buracos no caule] esbranquiçadas e/ou cicatrizes estipulares [cicatrizes das "escamas"] ao longo do ramo Magnolia champaca

45' - Ausência de lenticelas e cicatrizes estipulares ao longo do ramo

46. - Ocorrência de caulifloria [flores no caule]; folhas desenvolvidas com até $5 \mathrm{~mm}$ de largura Callistemon citrinus 46' - Ausência de caulifloria; folhas desenvolvidas com mais de $5 \mathrm{~mm}$ de largura

47. - Presença de tricomas aracnóides [pêlos em forma de teia de aranha] na face inferior da folha Licania tomentosa

47' - Ausência de tricomas aracnóides na folha

48. - Folhas, quando maceradas, liberam odor cítrico Citrus $\times$ limon 48 - Folhas, quando maceradas, não liberam odor cítrico

49. - Planta espinhenta, provida de brácteas coloridas [tipo especial de folhas na base das flores] Bougainvillea glabra 49' - Planta sem espinhos e desprovida de brácteas coloridas 50. - Folhas com mais de $9 \mathrm{~cm}$ de largura Terminalia catappa 50 ' - Folhas com até $7 \mathrm{~cm}$ de largura

51. - Folhas de margem inteira Chrysophyllum marginatum 51 ' - Folhas de margem denteada ou serrilhada

52. - Folha ovada com margem denteada Hibiscus rosa-sinensis 52 ' - Folha oval com margem serrilhada Cariniana estrellensis 29' - Folhas opostas

53. - Folhas com até $4 \mathrm{~mm}$ de largura Eugenia sprengelli

53 ' - Folhas com mais de $4 \mathrm{~mm}$ de largura

54. - Folhas opostas a subopostas, nunca cruzadas Psidium guajava

54' - Folhas opostas-cruzadas

55. - Folhas obovadas [forma oval de ponta-cabeça] Lagerstroemia indica

$55^{\prime}$ - Folhas de outros formatos

56. - Folhas densamente pilosas; base foliar cordada [em forma de coração]

Tibouchina grandifolia

56' - Folhas glabras [sem pêlos] a subglabras; base foliar atenuada ou arredondada

57. - Caule com secção transversal quadrada Tibouchina granulosa

$57^{\prime}$ - Caule com secção transversal arredondada 
58. - Presença de estípulas tricomiformes [escamas em forma de pêlo] nos nós interpeciolares [abaixo da haste da folha] Calycophyllum multiflorum 58' - Ausência de estípulas tricomiformes nos nós interpeciolares 59. - Caule com lenticelas [pequenas fendas ou buracos]; folhas com margens discolores [cor diferente daquela da lâmina] Ligustrum lucidum $59 '$ - Caule sem lenticelas; folhas nunca com margens discolores 60. - Caule não variegado Malpighia glabra 60 - Caule variegado [que descasca e que apresenta duas cores] 61. - Folhas com 7-8 pares de nervuras secundárias; pecíolo [haste] com 1-5 mm de comprimento Eugenia uniflora 61' - Folhas com mais de 20 pares de nervuras secundárias; pecíolo com 10-20 mm de comprimento

Syzygium cumini

\section{CONCLUSÕES}

Desde o seu início, este trabalho esteve focado em proporcionar ao público acesso a informações científicas sobre a arborização do centro de Campo Grande, com ênfase especial no reconhecimento das espécies arbóreas. Tal conhecimento pode vir a ser utilizado em aulas voltadas à educação ambiental (PESTANA; SOUZA, 2008), além de despertar a atenção dos pessoas para a diversidade da flora que compõe o paisagismo urbano.

\section{REFERÊNCIAS BIBLIOGRÁFICAS}

AGAREZ, F.V.; PEREIRA, C.; RIZZINI, C.M. Botânica: taxonomia, morfologia e reprodução das Angiospermae: chaves para determinação das famílias. 2. ed. Rio de Janeiro: Âmbirto Cultural, 1994.

ALMEIDA, S.P. et al. Cerrado: espécies vegetais úteis. Planaltina: Embrapa Pantanal, 1998.

APG III. An update of the Angiosperm Phylogeny Group classification for the orders and families of flowering plants: APG III. Botanical Journal of the Linnean Society, London, $n$. 161 , i. 2, p. 105-121, 2009.

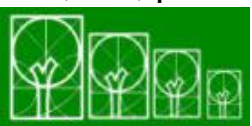

$\mathbf{S} \cdot \mathbf{B} \cdot \mathbf{A} \cdot \mathbf{U}$ Soc. Bras. de Arborização Urbana 
BACKES, P.; IRGANG, B. Árvores do Sul: Guia de Identificação \& Interesse Ecológico. Santa Cruz do Sul: Instituto Souza Cruz, 2002.

BARROS, E.A.S. Levantamento Fitossociológico em uma área do Parque dos Poderes (Campo Grande - MS). Campo Grande: UFMS, 1986.

BORTOLOTTO, I.M. Estudo de plantas nativas com valor ornamental em áreas de Cerrado no município de Campo Grande - Mato Grosso do Sul. Campo Grande: UFMS, 1987.

CARAUTA, J.P.P. Ficus (Moraceae) no Brasil: conservação e taxonomia. Albertoa, n. 2, p. 1-365, 1989.

ENERSUL - EMPRESA ENERGÉTICA DE MATO GROSSO DO SUL. Guia de Arborização Urbana: arborizando com responsabilidade. Campo Grande: ENERSUL, 2005. Disponível em: <http://www.gruporede.com.br/media/1086038/guia_net-2010.pdf>. Acesso em: 01 jun. 2011.

FORZZA, R.C. et al. Lista de Espécies da Flora do Brasil. Rio de Janeiro: Jardim Botânico do Rio de Janeiro, 2010.

GROSE, S.O.; OLMSTEAD, R.G. Taxonomic revisions in the polyphyletic genus Tabebuia s. I. (Bignoniaceae). Systematic Botany, v. 32, n. 3, p. 660-670, 2007.

GUEDES-BRUNI, R.R. et al. Inventário Florístico. In: SYLVESTRE, L.S. e ROSA, M.M.T. (orgs.). Manual Metodológico para Estudos Botânicos na Mata Atlântica. Rio de Janeiro: Seropédica, p. 24-49, 2002.

LEWIS, G. Legumes of the World. Richmond, Surrey: Royal Botanical Gardens Kew, 2005. $592 \mathrm{p}$.

LORENZI, H. Árvores Brasileiras: Manual de identificação e cultivo de plantas arbóreas do Brasil, Vol. 2. 3. ed. Nova Odessa: Instituto Plantarum, 2008. 
MABBERLEY, D.J. Mabberley's Plant-Book: A portable dictionary of plants, their classification and uses. 3. ed. Cambridge: Cambridge University Press, 2008.

MACHADO, J.W.B.; ALENCAR, F.O.C.C.; RODRIGUES, M.G.R. Árvores de Brasília. Brasília: Secretaria de Obras e Serviços Públicos, Depto. de Parques e Jardins, 1992.

MEIRA, M.A.A. et al. Diagnóstico da Arborização: Região Urbana do Centro. Campo Grande: PLANURB, 2001.

OLIVEIRA, A. Nelsinho inaugura Viveiro Flora do Cerrado no Dia da Árvore. CG Notícias, Campo Grande, 21 de setembro de 2010. Disponível em:

<http://www.prefeituradecampogrande.com.br/cgnoticias/noticiaCompleta?id_not=9145>. Acesso em: 01 jun. 2011.

PESTANA, L.T.C.; SOUZA, P.R. Ensino de botânica voltado à educação ambiental. Revista Aguapé, Campo Grande, n. 11, p. 4-5, 2008. Disponível em:

<http://www.scribd.com/doc/46079392/>. Acesso em: 01 jun. 2011.

PIVETTA, K.F.L.; SILVA FILHO, D.F. Boletim Acadêmico: Série Arborização Urbana. Jaboticabal: Unesp, 2002.

PLANURB - Instituto Municipal de Planejamento Urbano. Plano Local das Zonas Especiais de Interesse Cultural da Região Urbana do Centro ("Plano de Revitalização do Centro de Campo Grande"): Primeira Audiência Pública - 29/07/09 - Apresentação do Diagnóstico. Campo Grande: PLANURB, 2009. Disponível em:

<http://www.capital.ms.gov.br/egov/downloadFile.php?id=2165\&fileField=arquivo_dow\&table =downloads\&key=id_dow\&sigla_sec=centro>. Acesso em: 01 jun. 2011.

PMCG - Prefeitura Municipal de Campo Grande. Programa de Arborização Urbana. Campo Grande: PMCG, 2009. Disponível em: <http://www.prefeituradecampogrande.com.br/meioambiente/canaisTexto?id_can=3999>. Acesso em: 01 jun. 2011. 
POLHILL, R.M.; RAVEN, P.H. Advances in Legume Systematics, Part 1. Kew: Royal Botanical Gardens, 1981.

POTT, A.; POTT, V.J. Plantas do Pantanal. Corumbá: Embrapa Pantanal, 1994.

PRANCE, G.T. Árvores de Manaus. Manaus: INPA, 1975.

RODRIGUES, C.A.G. et al. Arborização urbana e produção de mudas de essências florestais nativas em Corumbá, MS. Corumbá: Embrapa Pantanal, 2002.

SEMADUR - SECRETARIA MUNICIPAL DE MEIO AMBIENTE E DESENVOLVIMENTO URBANO. Arborização Urbana: Guia Prático. Campo Grande: SEMADUR, 2010a.

Disponível em:

$<$ <ttp://www.prefeituradecampogrande.com.br/egov/downloadFile.php?id=2974\&fileField=arq uivo_dow\&table=downloads\&key=id_dow\&sigla_sec=dpsa>. Acesso em: 01 jun. 2011.

SEMADUR - SECRETARIA MUNICIPAL DE MEIO AMBIENTE E DESENVOLVIMENTO URBANO. Plano Diretor de Arborização Urbana de Campo Grande, MS (PDAU). Campo Grande: SEMADUR, 2010b. Disponível em:

<http://www.capital.ms.gov.br/egov/downloadFile.php?id=3103\&fileField=arquivo_dow\&table =downloads\&key=id_dow\&sigla_sec=dpsa>. Acesso em: 01 jun. 2011.

SILVA, A.M.M. Árvores de Campo Grande: Um olhar diferente. Campo Grande: Instituto Histórico e Geográfico de Mato Grosso do Sul, 2006.

SOUZA, V.C.; LORENZI, H. Botânica Sistemática: Guia ilustrado para identificação das famílias de Fanerógamas nativas e exóticas no Brasil, baseado em APG II. $2^{2}$. ed. Nova Odessa: Instituto Plantarum, 2008.

TAMASHIRO, J.Y.; SARTORI, Â.L.B. Árvores das ruas e praças de Poços de Caldas. Poços de Caldas: ALCOA, 1999.

TROPICOS.ORG. St. Louis: Missouri Botanical Garden, 2011. Disponível em: <http://www.tropicos.org/>. Acesso em: 01 jun. 2011. 
VELOSO, H.P. (org.). Manual Técnico da Vegetação Brasileira. Rio de Janeiro: IBGE, 1992.

VIBRANS, A.C. Apostila Dendrologia. Blumenau: FURB, 2010. Disponível em:

$<$ http://www.furb.br/florestal/dendrologia/apostila_dendrologia_agosto_2007.pdf>. Acesso em: 30 jul. 2010. 